\title{
Reflexiones traductológicas en torno al concepto de error cultural en extractos literarios comparados ${ }^{*}$
}

\author{
José María CASTELLANO MarTíNEZ \\ Universidad de Córdoba \\ 152camaj@uco.es \\ ORCID: 0000-0002-8179-1590
}

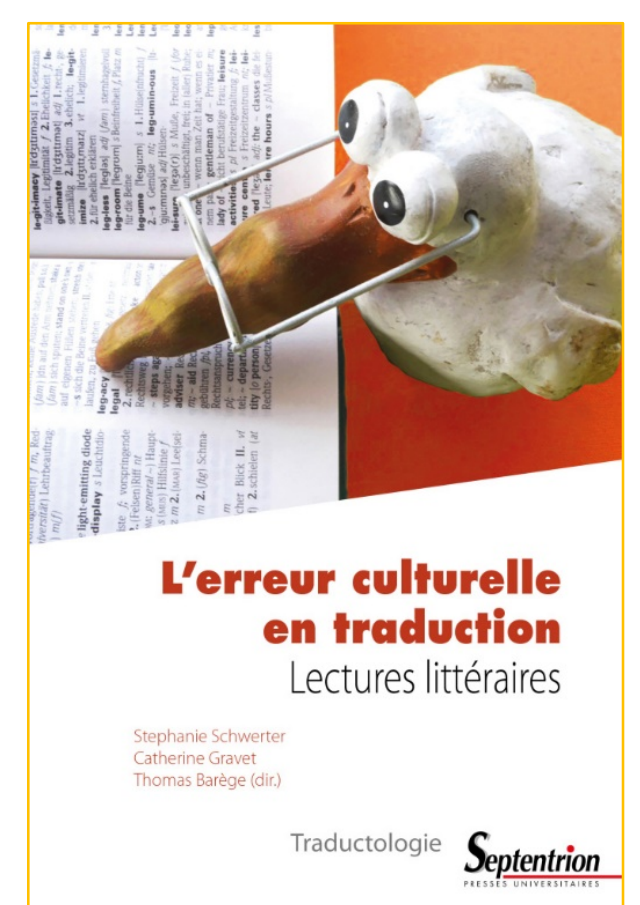

La presente obra es de especial interés para el campo de la Traductología con fines docentes e investigadores. En ella, una quincena de investigadores aborda la cuestión del error cultural en la traducción de textos literarios desde enfoques multidisciplinares y a partir de la revisión de los principales postulados teóricos. La reflexión sobre el origen del error de traducción en dicha materia -ya sea de naturaleza lingüística, textual o paratextual o de falta de bagaje cultural, entre otros-, así como su caracterización y tipología constituyen la razón de este volumen publicado 2019 por la editorial académica Septentrion.

La obra se organiza en torno a tres ejes temáticos: a) la manipulación en la traducción literaria (cap. 1-5), b) las discordancias culturales (cap. 6-10) y c) la alteridad cultural (cap. 11-15). La coordinación y dirección de la edición ha estado a cargo de Stephanie Schwerter y Thomas Barège de la Université Polytechnique Hauts-de-France, junto con Catherine Gravet de la Université de Mons. Estos tres profesores han desarrollado sus carreras académicas e investigadoras en el ámbito de la traductología, la transferencia cultural entre textos y la

\footnotetext{
* Acerca del libro de Stephanie Schwerter, Catherine Gravet y Thomas Barège (dir.), L'erreur culturelle en traduction. Lectures littéraires (Villeneuve d'Ascq, Presses Universitaires du Septentrion, 2019, 265 pp. ISBN: 978-2-7574-2952-5).
} 
intertextualidad en Literaturas, fundamentalmente de expresión francesa. La selección, edición y dirección de contribuciones en dichos ejes refleja con claridad las líneas de trabajo de los anteriores colegas, quienes también participan con sus respectivos capítulos en el libro tal y como se reseña a continuación.

El primer bloque temático, titulado Traductions, trahisons, manipulations, comienza con «La revision à l'épreuve de l'erreur culturelle» (pp. 19-34) se centra en la relatividad de la noción de error cultural en el contexto profesional de la traducción. Con tal fin, Nathalie Lemaire (Univ. libre de Bruxelles) aporta varios ejemplos sobre estrategias de revisión horizontal y vertical y ofrece una propuesta de tipología de errores culturales en textos literarios y artísticos a partir de un corpus de notas de traductor. Por su parte, en "Tout est dans la taille des carreaux. Les erreurs culturelles : un défi en traduction littéraire» (pp. 35-50), Stephanie Schwerter (Université Polytechnique Hauts-de-France) explora el error cultural en la novela corta Junior de Anna Gavalda, traducida a veintisiete lenguas. En especial, Schwerter presta especial atención a la traducción de imágenes, expresiones argóticas o títulos nobiliarios cuyas traducciones pueden distorsionar el sentido del original, tal y como reconoce en sus conclusiones. En una línea más tradicionalista, Asma Mejri Chaudey (Université de Tunis) explora mecanismos literarios y su transferencia entre los textos implicados en la traducción. En este capítulo, que lleva por título "Traduire les marqueurs de la littérarité. De la déformation à l'erreur culturelle» (pp. 51-63), la autora analiza la polifonía narrativa de Mahfouz en Les fils de la médina, con especial énfasis en el hecho intertextual del texto estudiado con respecto del Corán. Son múltiples los ejemplos en árabe dialectal egipcio y su traducción al francés, las referencias a mecanismos trópicos (metonimia, metáfora) o a la traducción de denominaciones como los nombres de los personajes.

La reflexión en torno a la noción de error cultural continúa en el siguiente capítulo, propuesto por Kossivi Apélété Gninevi (Université Paris Diderot) y titulado "L'erreur culturelle dans les traductions françaises de Things Fall Apart de Chinua Achebe» (pp. 65-76). En él, este doctorando reflexiona sobre el error cultural y las referencias culturales en las traducciones al francés de la novela anglófona Things Fall Apart del escritor nigeriano Chinua Achebe. La comparación de extractos seleccionados de las traducciones, en concreto, Le monde s'effondre (1972) y Tout s'effondre (2013), evidencian las deformaciones lingüísticas y culturales de los textos meta con respecto del original, ya sea por ignorancia, falta de conocimiento de la realidad del continente o por la expresión coloquial africana empleada en la obra. Este primer bloque se cierra con el trabajo de Isabelle Collombat (Université Sorbonne Nouvelle Paris 3), con título «La traduction littéraire comme art d'interprétation ou l'erreur assummée» (pp. 77-91). La autora realiza una revisión bibliográfica del concepto de «error cultural», del que ofrece varios ejemplos. Resulta de interés el cambio de perspectiva que la autora propone al reconocer la potencialidad interpretativa de la tra- 
ducción literaria. Por este motivo hace referencias a las licencias artísticas de la traducción de este tipo de textos o al arte de interpretación de los mismos a través del ideal de perfección. En definitiva, la asunción del error cultural representa el núcleo de la traducción como creación.

El segundo bloque temático se titula Entre erreur et errance (cap. 6-10) y comienza con el trabajo de Laurence Denooz (Université de Nantes), quien retoma el tema literario árabe. El capítulo "Interlangues et discordantes interculturelles. Le cas des littératures arabes» (pp. 95-108) esboza un marco teórico que parte de la divergencia cultural hacia la intraducibilidad, apoyándose en extractos de diferentes autores arabófonos y políglotas sobre esta cuestión (Barakat, Djebar, Tayyib, etc.). En definitiva, la interferencia de dichas lenguas - habida cuenta de los vacíos conceptuales, ambigüedades o falsos sentidos que existen entre ellas- genera un espacio de enriquecimiento artístico y cultural, en la misma línea que Collombat.

A mi juicio, el capítulo «La construction de l'Orient. L'erreur culturelle dans la traduction des ghazals de Hâfez par Henry Wilberforce Clarke» (pp. 109-1124) condensa el propósito principal de este bloque e incluso del volumen en sí. Laurence Chamlou (Université de Reims Champagne-Ardenne) establece un punto de partida para el estudio de la cuestión que nos ocupa en la archiconocida Orientalism de Edward Said (1978), de la que retoma el sentido de otredad occidental a través del pasado colonial. Los vínculos culturales entre la antigua Persia y el imperio colonial de Gran Bretańa constituyen un marco de transferencia cultural de interés para el autor, quien concluye que la poesía persa impregnó la británica a través de los orientalistas cuyos trabajos renovaron a lo largo del siglo XIX los géneros literarios ingleses.

Por su parte, Marc Lacheny (Universitér de Lorraine) aborda el error de traducción en la obra de Raimund en su capítulo «De Der Verschwender au Prodigue. Traduire Raimund, entre erreurs et licences du traducteur ?» (pp. 125-138). La poliedricidad del texto dramático de Raimund supone que el texto traducido reproduzca cierta musicalidad, fraseología, ritmo e incluso un conocimiento de alemán culto por parte del traductor. Asimismo, resulta de interés el análisis comparativo de la versión alemana respecto de las traducciones de Sylvie Muller y de Heinz Schwarzinger, en donde se aprecian divergencias de carácter cultural sobre las que reflexionar. Además del universo dramático, en este bloque también se contempla la realidad del cómic (BD) en «Traduction d'un jeu de mots dans la BD Docteur Schtroumpf: quelle douleur !» (pp. 125-138). Cristina Castellani (Univ. de Franche-Comté) muestra en este capítulo la complejidad de la traducción de aspectos culturales una vez se han considerado las limitaciones de este género para su traducción: los bocadillos propios del cómic - de los que ofrece una selección de ejemplos comparados en francés e italiano, la lengua Schtroumpt (en español: Pitufo) y las notas, como elementos paratextuales inseparables del conjunto de la obra. El segundo bloque, quizás el más ecléctico de los tres, concluye con «Comment Wang-Fô fut sauvé : l'erreur culturelle au cour des 
réécritures ?» (pp. 155-169), en donde Isabelle Chauveau (Université de Mons, Université Polytechnique Hauts-de-France) analiza las dos traducciones al español de Nouvelles Orientales realizadas por Emma Calatayud. En esta obra, Yourcenar recoge leyendas y mitos diversos, entre los cuales destaca Comment Wang-Fô fut sauvé por haber sido adaptada para el público infantil. Ambas versiones, la adulta y la infantil, son analizadas por Chauveau tanto en sus versiones originales como traducidas; incluso la autora propone una traducción propia para los extractos seleccionados. La adaptación de la versión adulta a la infantil ya implica cierta pérdida cultural y desaparición del exotismo en favor de la comprensión de los infantes. La historia de Wang-Fô es de temática controvertida por versar sobre el suicidio, el sacrificio, la muerte y la resurrección, cuya recepción difiere entre un público y otro, máxime entre las culturas oriental -en cuya tradición se inspira Yourcenar-y la occidental.

El último bloque temático de este volumen se denomina Traduire l'altérité culturelle (cap. 11-15) y está integrado por contribuciones en las que la figura del Otro se evidencia con mayor ahínco. Fayza El Qasem (Université Sorbonne Nouvelle Paris 3) presenta, en «Écriture de soi et autotraduction. Quelle marge de manœuvre pour l'auteur ? Le cas de La ceinture de l'écrivain saoudien Ahmed Abodehman» (pp. 173-186), la función del paratexto comprendido como herramienta de comunicación editorial a través de la cual la traducción no se limita sólo a la mera transferencia de significados, aproximándose en sus conclusiones a los postulados polisistémicos. Por su parte, Joëlle Popineau (Université de Tours) revisa de nuevo la noción de error de traducción en «L'erreur culturelle dans les traductions françaises et anglaises du roman de Johann Wolfgang von Goethe Die Leiden des jungen Werther» (pp. 187-210) y evidencia cómo a mayor distancia cronológica entre la versión original y el texto traducido, se incrementa la probabilidad de cometer errores culturales. Con ello, la autora pone de manifiesto la necesidad de llevar a cabo una labor de documentación histórica y lingüística suficiente para contextualizar el texto de llegada. A esta contribución le sigue un capítulo que versa sobre los giros culturales comunes en la traducción de dos géneros poéticos de la tradición argelina. En «L'erreur culturelle dans la traduction des textes du patrimoine populaire algérien» (pp. 211-224), Zeyneb Senouci Nereksi (Université de Tlemcen) reivindica la necesidad retraducir los tipos de textos líricos haoufi y haouzi para aproximarlos al contexto contemporáneo y ofrecer nuevas interpretaciones.

Si bien los capítulos integrantes de este bloque temático centran su interés en el Otro, la contribución «L'erreur culturelle, le traducteur et le titre» (pp. 225-242) recoge numerosos ejemplos de textología contrastiva en su estadio denominativo más puro: el estudio de los títulos. En él, Françoise Hammer (Université de Karlsruhe) recuerda la labor intermediaria del traductor -subordinado a intereses editoriales y limitaciones ajenas- y continúa con la revisión de estrategias traductológicas en los títulos de novelas policíacas por homología, adaptación, variación o innovación. La 
aplicación de estas metodologías conlleva el surgimiento de divergencias con respecto al título original en favor de otras nociones o imágenes en el de llegada. Finalmente, Catherine Gravet y Pauline Castel (Université de Mons) concluyen este volumen con «Le Roman de Renart: une retraduction en vers du romancier Alexis Curvers» (pp. 243-162). Las autoras estiman que la traducción poética es un ejercicio complejo cuyo resultado final implica para muchos una creación literaria en sí -en consonancia con Collombat y Denooz-, incluso si la traducción contuviera errores culturales o pérdidas con respecto del original, deberían asumirse como consecuencia de la limitación del verso en el nuevo texto.

En definitiva, el volumen aquí reseñado reúne un compendio de trabajos de nivel universitario y aplicabilidad múltiple, tanto en las aulas como en la investigación. La línea fundamental de trabajo se estructura en torno a la noción del error cultural en traducción literaria, para lo cual los autores revisan el concepto en su estadio teórico y práctico a través de los numerosos ejemplos y análisis contrastivos de versiones originales y traducidas en varias lenguas, destacando muy especialmente la árabe y francesa. Asimismo, los autores de los quince capítulos que integran L'erreur Culturelle en traduction. Lectures littéraires son representativos de instituciones universitarias de expresión francesa procedentes de diferentes rincones de Europa y África, lo cual pone en valor la relevancia de la investigación traductológica de lengua francesa frente a otras tendencias globalizadoras.

A tenor de todo lo anterior, y a mi juicio, esta obra complementa las bibliografías de los itinerarios y programas académicos de traducción y traductología de textos literarios, culturales, humanísticos o artísticos por cuanto aporta reflexión, análisis e innovación sobre una cuestión poco atendida en las guías docentes como es el error de traducción. 